\title{
Anti Surge Control of Centrifugal Compressor at PT. Pertamina EP Asset 2 Field Pendopo
}

\author{
Muhammad L. Hakim ${ }^{1}$, Balza Achmad ${ }^{1, *}$, and Juwari P. Sutikno ${ }^{2}$ \\ ${ }^{1}$ Department of Nuclear Engineering and Engineering Physics, Faculty of Engineering, Universitas Gadjah Mada, Yogyakarta, Indonesia \\ ${ }^{2}$ Department of Chemical Engineering, Sepuluh November Institute of Technology, Surabaya, Indonesia \\ *balzach@gmail.com (corresponding author)
}

\begin{abstract}
Gas Compression Package (GCP) is a vital system in the distribution of gas. Pertamina EP, in this regard as a state-owned company managing oil and gas on the upstream, is in the project phase of purchasing and installing compressor facilities. GCPs are used to increase gas pressure hence it can be transferred from gas wells to industrial areas. Dynamic analysis becomes important to observe the performance of the compressor and to ensure safety during operation, in order to avoid surge phenomenon. Surge is an undesirable phenomenon in the form of a backward flow of gas. The surge may damage the internal components of a centrifugal compressor, hence needs to be prevented from happening. The anti-surge controller manipulates anti-surge valve to give actions in the recycle lines when a surge occurred. PID controller is used for controlling and stabilizing the system. PID tuning is determined using Auto Tuning Variation method. This method is based on the process frequency response from relay oscillations. After the dynamic model of the plant had been developed, some simulations were carried out with various scenarios. The scenarios were based on a variety of issues that may occur in a gas compression system. The applied scenarios were a decrease in flow rate on the input side, a pressure drop in gas wells, and changes in gas composition. The control configuration of gas compression system was designed and modified in order to compensate disturbances and avoid surge phenomenon. Keywords-anti-surge, centrifugal compressor, dynamic simulation, PID controller.
\end{abstract}

\section{Introduction}

Natural gas is one of the natural resources that have a broad range of utilization such as for cooking, for generating electricity in power plants, and as raw material for processing of fertilizer. South Sumatra, a province in Indonesia, has very abundant natural resources, including natural gas. According to the government of South Sumatra Province, natural gas reserves are found in Musi Banyuasin, Lahat, Musi Rawas, and Ogan Ogan Ilir, which reach 7238 Billion Standard Cubic Feet per Day (BSCFD). The production during the last 4 years on average was 2,247,124 Million Metric Standard Cubic Feet per Day (MMSCFD) [1]. PT. Pertamina EP is a state-owned company which engaged in the upstream oil and gas. Currently, PT. Pertamina EP produced approximately 120,000 Barrels of oil Oil per Day (BOPD) and around 1,003 MMSCFD of natural gas [2]. PT. Pertamina EP plans to increase its production capacity of 100 MMSCFD to 150 MMSFD by building a new compressor facility in Assets 2 Field Pendopo. This project is divided into 3 main section, i.e., gas separator system, gas compression system, and fuel gas-seal gas system. This paper focuses on the gas compression system which consists of three trains. Each train consists of unit operations such as medium pressure (MP) scrubber, centrifugal compressor, air cooler, high pressure (HP) scrubber, level control valve (LCV), and anti-surge valve (ASV).
A centrifugal compressor is the main part that is very vital for transporting natural gas from well to industrial, commercial, and residential areas. During transportation, the pressure of the natural gas will decrease because of the friction that happens along the wall of pipes, the pressure drop in unit operation, slug flow, etc. Another vital problem is called surge phenomenon because it disrupts the transport of natural gas. Surging is an undesired event which occurs in the form of reverse flow from the discharge of compressor to the suction of compressor in centrifugal compressors and axial compressors.

Surging is undesirable because it can cause many problems. If no action is taken, the surge will result in damage to the internal components of the compressor. It is not desirable for the company as the internal components have to be changed often while the costs of internal compressor parts are very expensive. However, appropriate precautions can be taken into account to prevent the surge. There are few symptoms of a surge, i.e., there will be a low system flow, increases of discharge temperature, extreme changes in current motor, as well as violent fluctuations in discharge pressure.

Prevention of surging can be done by installing either blowdown valve (BDV) or ASV in the recycle pipe. 
However, BDV causes too much energy loss, because gas is discarded and accommodated in the tank. It is better to use ASV in order to minimize the waste of energy. ASV has a set point above the minimum flow which is regulated by a controller namely anti-surge controller (ASC). ASC controls the opening of ASV when some of the symptoms of surging are about to occur. The way to find out when the occurrence of surging is it can be observed on the compressor curve which is plot based on the flow versus head. In the compressor, the curve is divided into several lines to observe surge those are surge control line (SCL), backup line (BL), and surge line (SL). Surging can be observed when the flow falls to the set point so that the compressor operating point on the curve crosses the SL.

\section{Methodology}

This research was conducted in several steps, i.e., developing dynamic models, analysis of the performance of PID controllers, and performing simulation scenario.

The initial simulation model was created in a steady state. The processes that occur in HYSYS simulation follow thermodynamic laws, mass balance, and energy balance. The dynamic simulation was then created by inputting data from Pertamina project into this initial model. In order to make a dynamic simulation, it needed sizing data of the unit operations and valves, the piping data, compressor performance, and the surge flow data which obtained from the vendor. The dynamic model that had been created should be stabilized by designing a PID controller.

There were some controlled parameters such as level, pressure, temperature, flow, and speed of the compressor in the plant. PID control parameters were determined using Auto Tuning Variation (ATV) method. A PID ATV method developed by Astrom-Hagglund is one of the auto-tuning technique that is simple and most appropriate to control process, which has been successfully applied to industries for over 15 years. This method is based on the response of process frequency of oscillation relays [3-6].

The last step was performing simulations with various scenarios. The scenarios were based on the problems that might occur in a gas compression system, i.e., a decrease in flow rate, a pressure drop in gas wells, and changes in input gas compositions. The scenarios can be analyzed in terms of operation and safety design modifications offered when compared to existing designs.

\section{Results and Discussion}

In order to determine the control parameter which is employed are based on the process conditions and design demands. PI controllers are commonly used in industries rather PID controllers because of many factors such as the tolerated offset, the presence of noise, excessive dead time, and small capacity.

After determining control parameters, the next step is tuning with Auto Tuning Variation (ATV) method, while for Anti-Surge Controller (ASC) tuning done by trial and error with certain procedures. Similar to Ziegler-Nichols method in PID tuning, ATV method employs $K_{c u}$ and $P_{u}$. $K_{c u}$ is controller gain that Products the limit cycle, while $P_{u}$ is the period taken from limit cycle. The following calculations are to determine the ultimate period $P_{u}$, ultimate gain $K_{c u}$, controller gain $K_{c}$, and integral time $T_{i}$.

$$
\begin{aligned}
& K_{c}=\frac{K_{u}}{3,2} \\
& T_{i}=2,2 P_{u}
\end{aligned}
$$

The control parameters followed the formulas as in Table 1. It is recommended for use Tyreus-Luyben formula for tuning that suitable for unit operation in Chemical process [7].

Table 1. Settings of PID controller based on the continuous cycle method [4]

\begin{tabular}{|c|c|c|c|}
\hline Ziegler-Nichols & $\boldsymbol{K}_{\boldsymbol{c}}$ & $\boldsymbol{T}_{\boldsymbol{i}}$ & $\boldsymbol{T}_{\boldsymbol{d}}$ \\
\hline P & $0,5 K_{c u}$ & - & - \\
PI & $0,45 K_{c u}$ & $P_{u} / 1,2$ & - \\
PID & $0,6 K_{c u}$ & $P_{u} / 2$ & $P_{u} / 8$ \\
\hline Tyreus-Luyben & $\boldsymbol{K}_{\boldsymbol{c}}$ & $\boldsymbol{T}_{\boldsymbol{i}}$ & $\boldsymbol{T}_{\boldsymbol{d}}$ \\
\hline PI & $0,31 K_{c u}$ & $2,2 P_{u}$ & - \\
PID & $0,45 K_{c u}$ & $2,2 P_{u}$ & $P_{u} / 6,3$ \\
\hline
\end{tabular}

For the algorithm of PID controller for the autotuning method, there is some additional parameter for PID controller algorithm, that is phase margin $\varphi_{m}$ and design parameter $\alpha$. The equation to determine the PID controller using ATV is as follows [7].

$$
\begin{gathered}
K_{c}=K_{c u} \cos \left(\varphi_{m}\right) \\
T_{i}=\alpha T_{d} \\
T_{d}=\frac{\tan \left(\varphi_{m}\right) \sqrt{(4 / \alpha)+\tan \left(\varphi_{m}\right)}}{2 \omega_{c}} \\
\omega_{c}=\frac{2 \pi}{P_{u}}
\end{gathered}
$$

Based on the formula and algorithm for PID tuning obtained the value of $\mathrm{K}_{c}, \mathrm{~T}_{\mathrm{i}}$, and $\mathrm{T}_{\mathrm{d}}$ for all of the controller. There are total 24 controllers in the modified design which is eight controllers in each train. The value of $\mathrm{K}_{\mathrm{c}}, \mathrm{T}_{\mathrm{i}}$, and $\mathrm{T}_{\mathrm{d}}$ are summarized in Table 2.

The dynamic model created in the process simulator and the scheme of gas compression systems are presented in Fig. 1 and Fig. 2. 
Table 2. The results of tuning all control parameters

\begin{tabular}{|c|c|c|c|c|c|c|c|c|c|c|}
\hline No & Label & Mode & SP Mode & SP & PV & OP & Controller & Kc & $\mathbf{T i}$ & Td \\
\hline 1 & LIC-2331 & Auto & Sp Local & 1000 & 1000.003 & 16.3094 & PI & 31.1 & 0.802 & \\
\hline 2 & LIC-2361 & Auto & Sp Local & 825 & 824.994 & 44.5636 & PI & 77.2 & 1.83 & \\
\hline 3 & LIC-2231 & Auto & Sp Local & 1000 & 1000.212 & 17.8985 & PI & 31.8 & 0.828 & \\
\hline 4 & LIC-2261 & Auto & Sp Local & 825 & 824.927 & 45.1033 & PI & 75.4 & 1.56 & \\
\hline 5 & LIC-2131 & Auto & Sp Local & 1000 & 999.987 & 16.6827 & PI & 22.7 & 0.512 & \\
\hline 6 & LIC-2161 & Auto & Sp Local & 825 & 824.991 & 43.9585 & PI & 75.6 & 1.55 & \\
\hline 7 & $\begin{array}{l}\text { K-234: Surge } \\
\text { Controller }\end{array}$ & Auto & Sp Local & 67314.236 & 97621.723 & 0 & PI & 4 & 1.5 & \\
\hline 8 & $\begin{array}{l}\text { K-224: Surge } \\
\text { Controller }\end{array}$ & Auto & Sp Local & 67330.445 & 99202.221 & 0 & PI & 4 & 1.5 & \\
\hline 9 & $\begin{array}{l}\text { K-214: Surge } \\
\text { Controller }\end{array}$ & Auto & Sp Local & 67294.184 & 97911.148 & 0 & PI & 4 & 1.5 & \\
\hline 10 & TIC-2351 & Auto & Sp Local & 113 & 113.000 & 63.1747 & PID & 0.627 & 0.169 & $3.75 \times 10^{-2}$ \\
\hline 11 & PIC-1101 & Auto & Sp Local & 305 & 305.001 & 39.7273 & PI & 0.85 & $7.87 \times 10^{-3}$ & \\
\hline 12 & TIC-2251 & Auto & Sp Local & 113 & 112.892 & 60.651 & PID & 1.64 & 0.103 & $2.29 \times 10^{-2}$ \\
\hline 13 & PIC-0801 & Auto & Sp Local & 305 & 305.006 & 41.8596 & PI & 0.848 & $7.88 \times 10^{-3}$ & \\
\hline 14 & TIC-2151 & Auto & Sp Local & 113 & 113.001 & 62.9069 & PID & 0.955 & 0.119 & $2.63 \times 10^{-2}$ \\
\hline 15 & PIC-0501 & Auto & Sp Local & 305 & 305.001 & 41.0462 & PI & 0.849 & $5.63 \times 10^{-3}$ & \\
\hline 16 & PIC-2241 & Auto & Sp Local & 771 & 771.272 & 80.1118 & PI & 0.193 & $3.81 \times 10^{-2}$ & \\
\hline 17 & SIC-2241 & Auto & Sp Remote & 11455.994 & 11456.349 & 50.3773 & PI & 0.632 & $6.49 \times 10^{-3}$ & \\
\hline 18 & PIC-2341 & Auto & Sp Local & 771 & 771.000 & 79.6821 & PI & 0.197 & $5.65 \times 10^{-2}$ & \\
\hline 19 & SIC-2341 & Auto & Sp Remote & 11394.536 & 11394.536 & 49.557 & PI & 0.705 & $7.32 \times 10^{-3}$ & \\
\hline 20 & PIC-2141 & Auto & Sp Local & 771 & 771000 & 79.7459 & PI & 0.19 & $3.58 \times 10^{-2}$ & \\
\hline 21 & SIC-2141 & Auto & Sp Remote & 11403.663 & 11403.663 & 49.7234 & PI & 0.679 & $6.30 \times 10^{-3}$ & \\
\hline 22 & TIC-2251-1 & Auto & Sp Local & 93.25 & 93.309 & 57.122 & PID & 3.07 & $1.39 \times 10^{-1}$ & $3.10 \times 10^{-2}$ \\
\hline 23 & TIC-2351-1 & Auto & Sp Local & 93.25 & 93.250 & 57.5831 & PID & 3.09 & $1.39 \times 10^{-1}$ & $3.09 \times 10^{-2}$ \\
\hline 24 & TIC-2151-1 & Auto & Sp Local & 93.25 & 92.880 & 53.8588 & PID & 3.07 & $1.39 \times 10^{-1}$ & $3.10 \times 10^{-2}$ \\
\hline
\end{tabular}

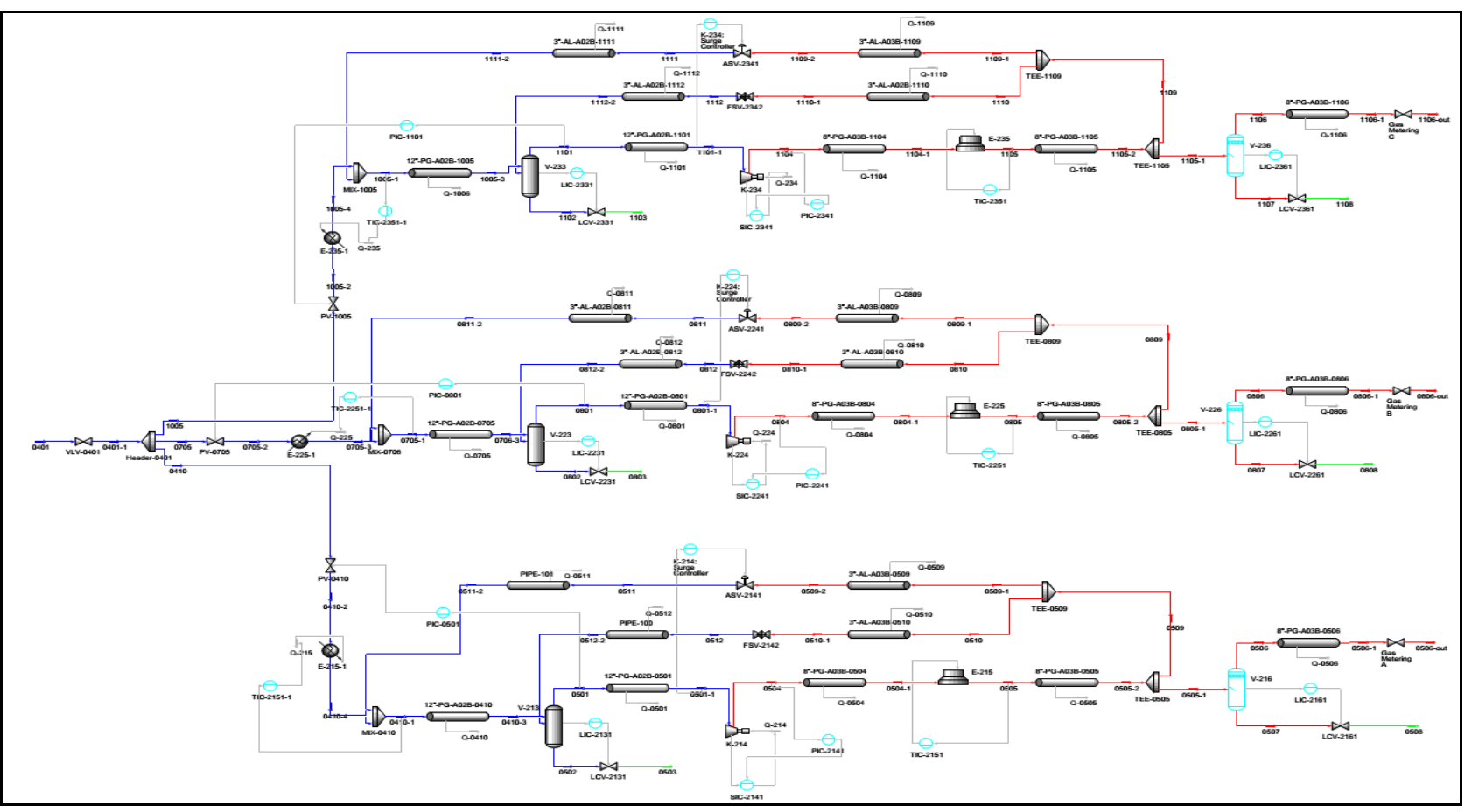

Fig. 1. The dynamic model of three train gas compression system 


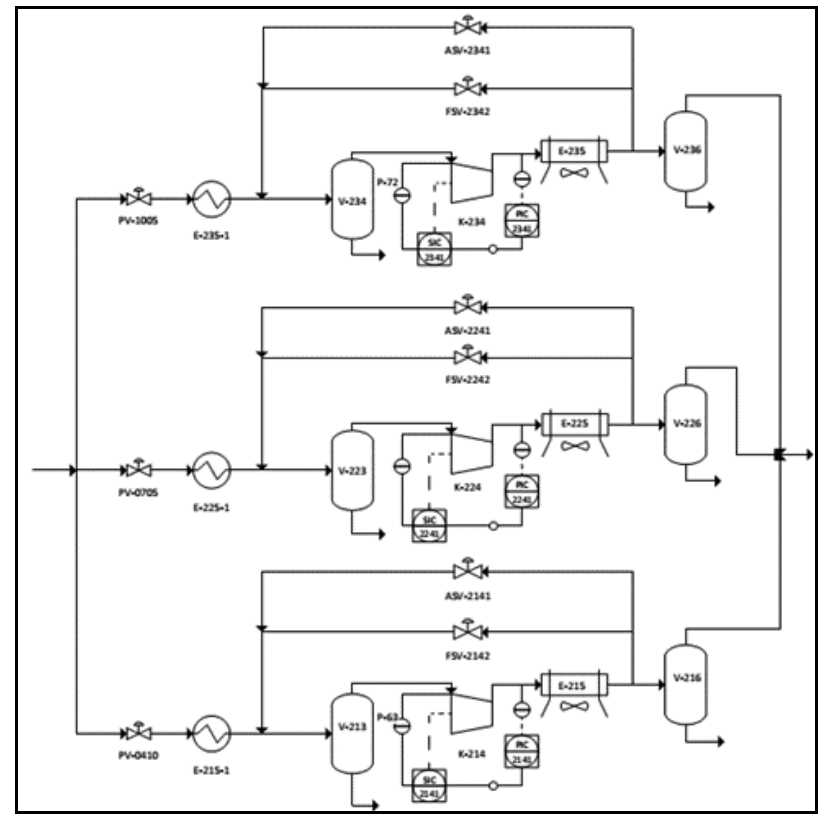

Fig. 2. Scheme of three train gas compression system

\subsection{Scenario 1 : modified design}

This first scenario demonstrated the importance of modified design in creating the model using HYSYS [8-11].

1) Case 1: By using load sharing, the flow rate was decreased by $62 \%$ from 153.3 MMSCFD to 58.28 $M M S C F D$

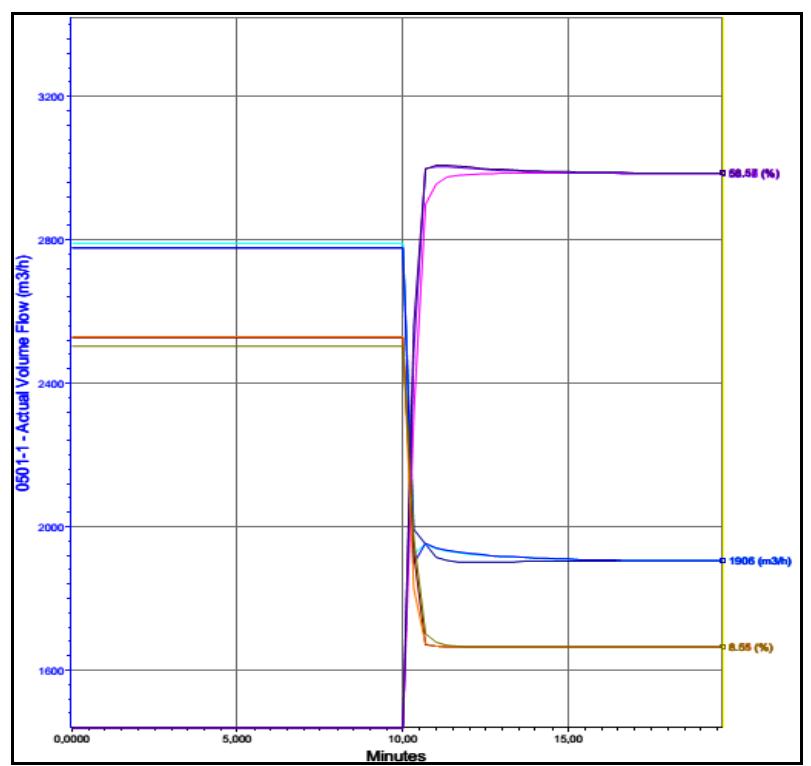

Fig. 3. The Result of load sharing for three train compressors

Fig. 3 shows the result of the simulation with three load sharing. When the flow rate dropped to a certain value, it caused surging. The above simulation conducted for 20 minutes by decreasing the flow rate from 153.3 MMSCFD to 58.28 MMSCFD. When surging was about to happen, ASV 2141, ASV-2241, ASV 2341 aggressively opened at $58.94 \%, 59.27 \%, 55.32 \%$ to prevent surging. The purpose of the installation of gas compression systems in parallel was to balance the load. When there was a surging, the pressure control valve (PV) would be split into three train loads with equal load with current openings steady at $8.5 \%$.

2) Case 2: The flow rate of the working fluid was reduced from $153.2 M M S C F D$ to be 65.71 MMSCFD, or reduced by $57.108 \%$ and the valve on the discharge failed.

Table 3 and Table 4 show the comparison between the system which was equipped with control performance and load sharing, and the system without them. Compressor discharge pressure increased when the flow decreased, and discharge valve failed. In Table 4 , when the pressure rose because of discharge valve failed, it can be overcome by increasing the RPM of the compressor. In Table 4, pressure rise cannot be anticipated, thus exceeding the design pressure of the unit operation in the discharge. This will certainly endanger the operating unit.

Table 3. The pressure of each train without control performance and load sharing

\begin{tabular}{|l|c|c|c|}
\hline \multicolumn{1}{|c|}{ Parameter } & K-214 & K-224 & K-234 \\
\hline $\begin{array}{l}\text { Compressor Suction Pressure } \\
\text { (psig) }\end{array}$ & 317.4 & 317.5 & 317.6 \\
\hline Max Pressure. (psig) & 320.3 & 320.3 & 320.3 \\
\hline $\begin{array}{l}\text { Compressor Discharge } \\
\text { Pressure (psig) }\end{array}$ & 967.9 & 971 & 968.3 \\
\hline $\begin{array}{l}\text { Min Discharge Pressure } \\
\text { (psig) }\end{array}$ & 750.0 & 750.0 & 750.0 \\
\hline $\begin{array}{l}\text { Air Cooler Operating } \\
\text { Pressure (psig) }\end{array}$ & 770.0 & 770.0 & 770.0 \\
\hline $\begin{array}{l}\text { Air Cooler Design Pressure } \\
\text { (psig) }\end{array}$ & 950.0 & 950.0 & 950.0 \\
\hline $\begin{array}{l}\text { HP Scrubber OPerating } \\
\text { Pressure (psig) }\end{array}$ & 760.0 & 760.0 & 760.0 \\
\hline $\begin{array}{l}\text { HP Scrubber Design Pressure } \\
\text { (psig) }\end{array}$ & 950.0 & 950.0 & 950.0 \\
\hline
\end{tabular}

Table 4. The pressure of each train to control the performance and load sharing

\begin{tabular}{|l|c|c|c|}
\hline \multicolumn{1}{|c|}{ Parameter } & K-214 & K-224 & K-234 \\
\hline $\begin{array}{l}\text { Compressor Suction Pressure } \\
\text { (psig) }\end{array}$ & 304.9 & 304.9 & 304.9 \\
\hline Max Pressure. (psig) & 320.3 & 320.3 & 320.3 \\
\hline $\begin{array}{l}\text { Compressor Discharge } \\
\text { Pressure (psig) }\end{array}$ & 771.0 & 771.0 & 771.0 \\
\hline $\begin{array}{l}\text { Min Discharge Pressure } \\
\text { (psig) }\end{array}$ & 750.0 & 750.0 & 750.0 \\
\hline $\begin{array}{l}\text { Air Cooler Operating } \\
\text { Pressure (psig) }\end{array}$ & 770.0 & 770.0 & 770.0 \\
\hline $\begin{array}{l}\text { Air Cooler Design Pressure } \\
\text { (psig) }\end{array}$ & 950.0 & 950.0 & 950.0 \\
\hline $\begin{array}{l}\text { HP Scrubber OPerating } \\
\text { Pressure (psig) }\end{array}$ & 760.0 & 760.0 & 760.0 \\
\hline $\begin{array}{l}\text { HP Scrubber Design Pressure } \\
\text { (psig) }\end{array}$ & 950.0 & 950.0 & 950.0 \\
\hline
\end{tabular}

3) Case 3: Comparison of design in the case of denser gas in the train $K-224$

Table 5 provides the comparison of the two systems when the molecular weight of gas is varied. It can be inferred; the modified design is more efficient compared to the existing design due to pressure ratio and the power needed to operate each compressor. 
Table 5. The pressure of each train to control the performance and load sharing

\begin{tabular}{|l|c|c|}
\hline \multicolumn{1}{|c|}{ Parameter } & $\begin{array}{c}\text { Existing } \\
\text { Design }\end{array}$ & $\begin{array}{c}\text { Modified } \\
\text { Design }\end{array}$ \\
\hline Adiabatic Efficiency (\%) & 70.69 & 71.388 \\
\hline Polytropic Efficiency (\%) & 73.147 & 73.799 \\
\hline Power (kW) & $2,345.19$ & $2,256.99$ \\
\hline Suction Pressure (psig) & 307.2 & 304.9 \\
\hline Discharge Pressure (psig) & 772.5 & 771 \\
\hline Pressure Ratio & 2.446 & 2.459 \\
\hline
\end{tabular}

\subsection{Scenario 2 : Low Suction Pressure}

On the second scenario, it is observed how the system responds to disturbances in the form of low suction pressure. Any disturbance can cause a surge, so the role of the AntiSurge Controller (ASC) and Anti-Surge Valve (ASV) is important to overcome surge. ASC has parameters named surge control parameter $(\mathrm{A}, \mathrm{B}, \mathrm{C}, \mathrm{D})$ which must be calculated by the user. The equation of surge control parameters is mathematically written as follows.

$$
h_{m}=A+B \times F_{s}+C \times F_{s}^{2}+D \times F_{s}^{3}
$$

Where $F_{s}\left(\mathrm{~m}^{3} / \mathrm{s}\right)$ is the surge flow, $h_{m}(\mathrm{~m})$ is the head, and $A$ (m), $B\left(\mathrm{~m} / \mathrm{m}^{3} / \mathrm{s}\right), C\left(\mathrm{~m} / \mathrm{m}^{6} / \mathrm{s}^{2}\right)$, and $D\left(\mathrm{~m} / \mathrm{m}^{9} / \mathrm{s}^{3}\right)$ are surge control parameters set by the user. Table 6 provides the result of surge control parameter.

Table 6. Surge Control Parameters

\begin{tabular}{|c|l|c|}
\hline No & \multicolumn{1}{|c|}{ Parameter } & Value \\
\hline 1 & Parameter A $(\mathrm{m})$ & $-28,134.9$ \\
\hline 2 & Parameter B $\left(\mathrm{m} / \mathrm{m}^{3} / \mathrm{s}\right)$ & 113,450 \\
\hline 3 & Parameter C $\left(\mathrm{m} / \mathrm{m}^{6} / \mathrm{s}^{2}\right)$ & $-57,205.7$ \\
\hline 4 & Parameter D $\left(\mathrm{m} / \mathrm{m}^{9} / \mathrm{s}^{3}\right)$ & 0 \\
\hline 5 & Control Line $(\%)$ & 10 \\
\hline 6 & Backup Line $(\%)$ & 8 \\
\hline 7 & Quick Opening $(\%)$ & 40 \\
\hline
\end{tabular}

It can be observed from Fig. 4 and Fig. 5 when a low suction pressure is occurring, the flow rate will decrease temporarily. At a certain value of the decreasing of flow rate, it will cause surge $[9,10]$. It can be observed that the blue line (actual volume flow) approaches the green line (the set point of surge controller). In order to prevent surge, ASV-2141, ASV-2241, and ASV-2341 aggressively opened at $76,6 \%, 55,22 \%, 65,63 \%$.

There is a limit of decreasing of low suction pressure. The safety factor is one of the considerations that commonly used to limit the margin of operation $[12,13]$. Generally, the safety factor is set to $5 \%$ to $10 \%$. The design temperature for unit operation air cooler and HP scrubber is $300^{\circ} \mathrm{F}$. Table 7 presents the safety factor for operating temperature for the system. In order to meet the demand of safety factor, discharge pressure that allowed is set $260-281$ psig, and the suction pressure is set 246.1 to 267.8 psig hence that the temperature generated in the discharge of $270-285^{\circ} \mathrm{F}$.

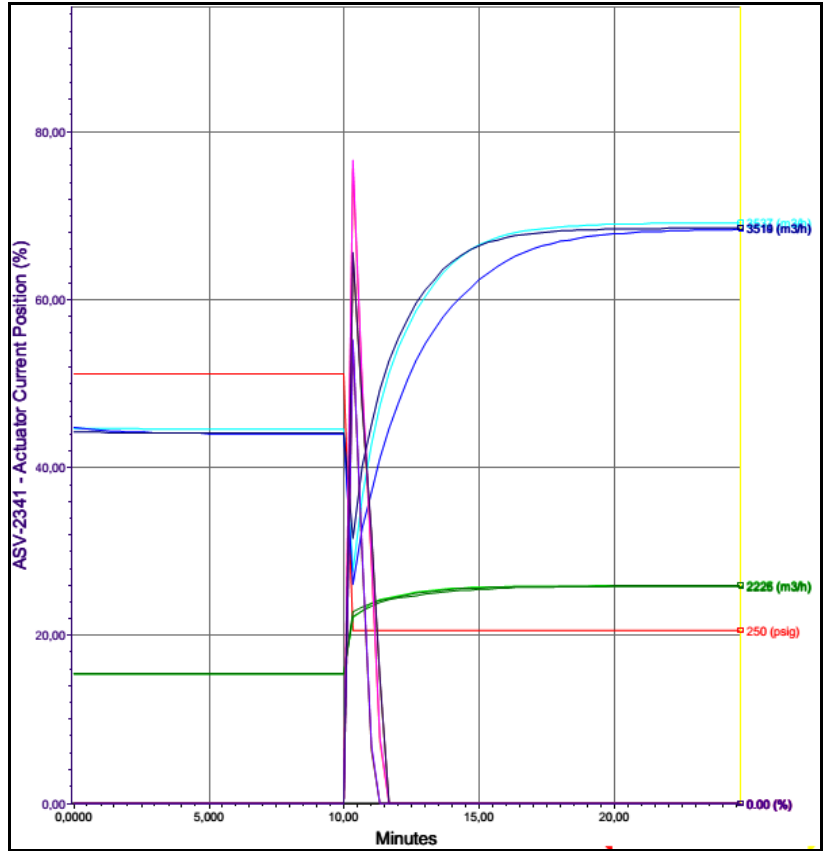

Fig. 4. The result of low suction pressure simulation

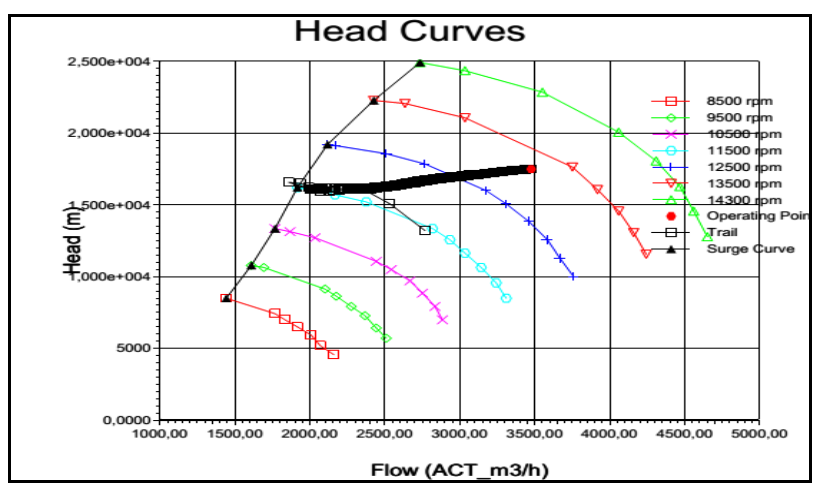

Fig. 5. Compressor performance for the low suction pressure

Table 7. Safety factor for The pressure of each train to control the performance and load sharing

\begin{tabular}{|c|c|c|c|}
\hline \multicolumn{4}{|c|}{$10 \%$ Safety Factor for Temperature } \\
\hline & Inlet & Suction & Discharge \\
\hline Temperature $(\mathrm{F})$ & 101.2 & 93.12 & 270 \\
\hline Tekanan (psig) & 281 & 267.8 & 771 \\
\hline $\begin{array}{l}\text { Molar Flow } \\
\text { (MMSCFD) }\end{array}$ & 151 & 49.93 & 49.93 \\
\hline \multicolumn{4}{|c|}{$5 \%$ Safety Factor for Temperature } \\
\hline & Inlet & Suction & Discharge \\
\hline Temperatur (F) & 101.2 & 93.04 & 285 \\
\hline Tekanan (psig) & 260 & 246.1 & 771 \\
\hline $\begin{array}{l}\text { Molar Flow } \\
\text { (MMSCFD) }\end{array}$ & 149.5 & 49.27 & 49.26 \\
\hline
\end{tabular}

\subsection{Scenario 3 : Change in Composition of Fluid}

In Scenario 3, the simulation was conducted in order to observe the effect of a change in the composition of the fluid. Gas with heavier molecular weight named denser gas (+2 $\mathrm{g} / \mathrm{mol})$, otherwise gas with lighter molecular weight named leaner gas $(-2 \mathrm{~g} / \mathrm{mol})$. 
1) Case 1: leaner Gas $\left(15,92 \mathrm{~kg} / \mathrm{m}^{3}\right)$ and low molecular weight $(17,06 \mathrm{~g} / \mathrm{mol})$

Leaner gas contains very high methane about $95.496 \%$ and slight water content as shown in Table 8. Fig. 6 shows the performance of the compressor when the composition is changed to $-2 \mathrm{~g} / \mathrm{mol}$. Gas with the lighter molecular weight will be easier to push. Thus, it does not need much discharge pressure. It has implications for the design demands; the pressure generated becomes less. Therefore, the RPM of the compressor will be increased by a speed controller, so greater flow rate occurs, then the pressure generated will reach the set point.

Table 8. Gas well composition with a molecular weight of 17.06 $\mathrm{g} / \mathrm{mol}$

\begin{tabular}{|c|c|c|c|c|}
\hline & $\begin{array}{c}\text { Mol } \\
\text { fraction } \\
\text { (mol \%) }\end{array}$ & $\begin{array}{c}\text { Gas phase } \\
\text { (mol \%) }\end{array}$ & $\begin{array}{c}\text { Liquid } \\
\text { phase } \\
\mathbf{\%} \text { (mol }\end{array}$ & $\begin{array}{c}\text { Water } \\
\text { (mol \%) }\end{array}$ \\
\hline Methane & $77.771 \%$ & $78.067 \%$ & $8.413 \%$ & $0.000 \%$ \\
\hline Ethane & $9.291 \%$ & $9.319 \%$ & $4.498 \%$ & $0.000 \%$ \\
\hline Propane & $4.096 \%$ & $4.100 \%$ & $6.050 \%$ & $0.000 \%$ \\
\hline i-Butane & $0.549 \%$ & $0.548 \%$ & $1.819 \%$ & $0.000 \%$ \\
\hline n-Butane & $0.649 \%$ & $0.646 \%$ & $2.899 \%$ & $0.000 \%$ \\
\hline i-pentane & $0.216 \%$ & $0.213 \%$ & $2.143 \%$ & $0.000 \%$ \\
\hline n-pentane & $0.167 \%$ & $0.163 \%$ & $2.103 \%$ & $0.000 \%$ \\
\hline n-hexane & $0.200 \%$ & $0.187 \%$ & $6.694 \%$ & $0.000 \%$ \\
\hline n-Heptane & $0.383 \%$ & $0.320 \%$ & $30.689 \%$ & $0.000 \%$ \\
\hline n-Octane & $0.083 \%$ & $0.054 \%$ & $13.850 \%$ & $0.000 \%$ \\
\hline n-Nonane & $0.050 \%$ & $0.021 \%$ & $13.749 \%$ & $0.000 \%$ \\
\hline n-Decane & $0.017 \%$ & $0.004 \%$ & $6.131 \%$ & $0.000 \%$ \\
\hline n-C11 & $0.000 \%$ & $0.000 \%$ & $0.000 \%$ & $0.000 \%$ \\
\hline H2S & $0.000 \%$ & $0.000 \%$ & $0.000 \%$ & $0.000 \%$ \\
\hline H2O & $0.516 \%$ & $0.325 \%$ & $0.089 \%$ & $99.976 \%$ \\
\hline Nitrogen & $2.897 \%$ & $2.909 \%$ & $0.109 \%$ & $0.001 \%$ \\
\hline CO2 & $3.114 \%$ & $3.125 \%$ & $0.765 \%$ & $0.023 \%$ \\
\hline
\end{tabular}

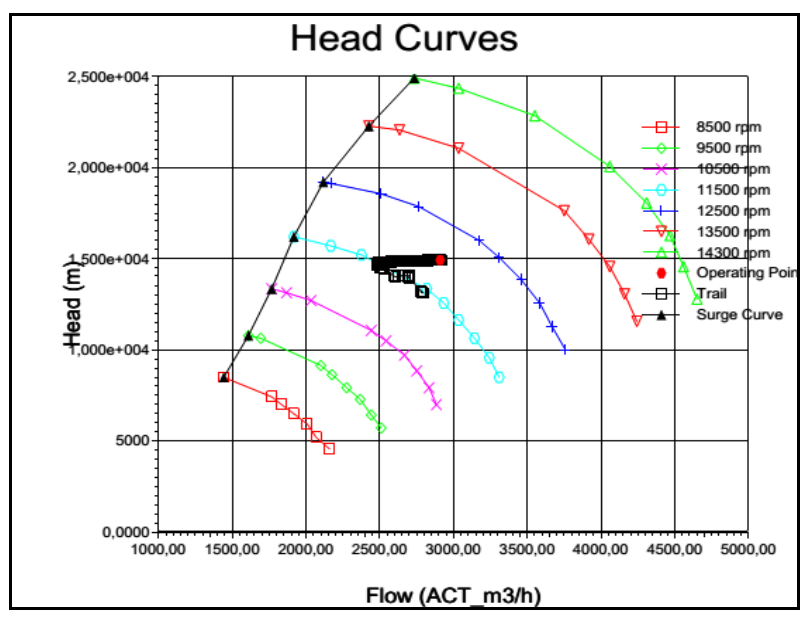

Fig. 6. Compressor Performance with a change in composition -2 $\mathrm{g} / \mathrm{mol}$

2) Case 2: Denser gas $\left(15,92 \mathrm{~kg} / \mathrm{m}^{3}\right)$ and high molecular weight $(21,06 \mathrm{~g} / \mathrm{mol})$

Otherwise, the denser gas contains methane, which is smaller than normal around $77.771 \%$ and more water content than normal as shown in Table 9. When the gas composition changed by increasing the molecular weight becomes $+2 \mathrm{~g} / \mathrm{mol}$, it will have implications for the discharge pressure required more effort to depress the gas (Fig. 7). Thus the pressure would exceed the demands of the design. Therefore, the RPM of the compressor will be decreased by speed controller causes the flow rate become small so that the pressure generated in will reach the set points.

Table 9. Gas well composition with a molecular weight of 21.06 $\mathrm{g} / \mathrm{mol}$

\begin{tabular}{|l|c|c|c|c|}
\hline & $\begin{array}{c}\text { Mol } \\
\text { fraction } \\
\text { (mol \%) }\end{array}$ & $\begin{array}{c}\text { Gas phase } \\
\text { (mol \%) }\end{array}$ & $\begin{array}{c}\text { Liquid } \\
\text { phase (mol } \\
\mathbf{\%})\end{array}$ & $\begin{array}{c}\text { Water (mol } \\
\mathbf{\%})\end{array}$ \\
\hline Methane & $95.496 \%$ & $95.496 \%$ & $25.295 \%$ & $0.000 \%$ \\
\hline Ethane & $1.883 \%$ & $1.883 \%$ & $2.207 \%$ & $0.000 \%$ \\
\hline Propane & $0.830 \%$ & $0.830 \%$ & $2.979 \%$ & $0.000 \%$ \\
\hline i-Butane & $0.111 \%$ & $0.111 \%$ & $0.909 \%$ & $0.000 \%$ \\
\hline n-Butane & $0.132 \%$ & $0.132 \%$ & $1.441 \%$ & $0.000 \%$ \\
\hline i-pentane & $0.044 \%$ & $0.044 \%$ & $1.090 \%$ & $0.000 \%$ \\
\hline n-pentane & $0.034 \%$ & $0.034 \%$ & $1.071 \%$ & $0.000 \%$ \\
\hline n-hexane & $0.040 \%$ & $0.040 \%$ & $3.605 \%$ & $0.000 \%$ \\
\hline n-Heptane & $0.078 \%$ & $0.078 \%$ & $18.704 \%$ & $0.000 \%$ \\
\hline n-Octane & $0.017 \%$ & $0.017 \%$ & $10.938 \%$ & $0.000 \%$ \\
\hline n-Nonane & $0.010 \%$ & $0.010 \%$ & $16.970 \%$ & $0.000 \%$ \\
\hline n-Decane & $0.003 \%$ & $0.003 \%$ & $14.288 \%$ & $0.000 \%$ \\
\hline n-C11 & $0.000 \%$ & $0.000 \%$ & $0.000 \%$ & $0.000 \%$ \\
\hline H2S & $0.000 \%$ & $0.000 \%$ & $0.000 \%$ & $0.000 \%$ \\
\hline H2O & $0.105 \%$ & $0.105 \%$ & $0.069 \%$ & $99.985 \%$ \\
\hline Nitrogen & $0.587 \%$ & $0.587 \%$ & $0.056 \%$ & $0.000 \%$ \\
\hline CO2 & $0.631 \%$ & $0.631 \%$ & $0.380 \%$ & $0.014 \%$ \\
\hline
\end{tabular}

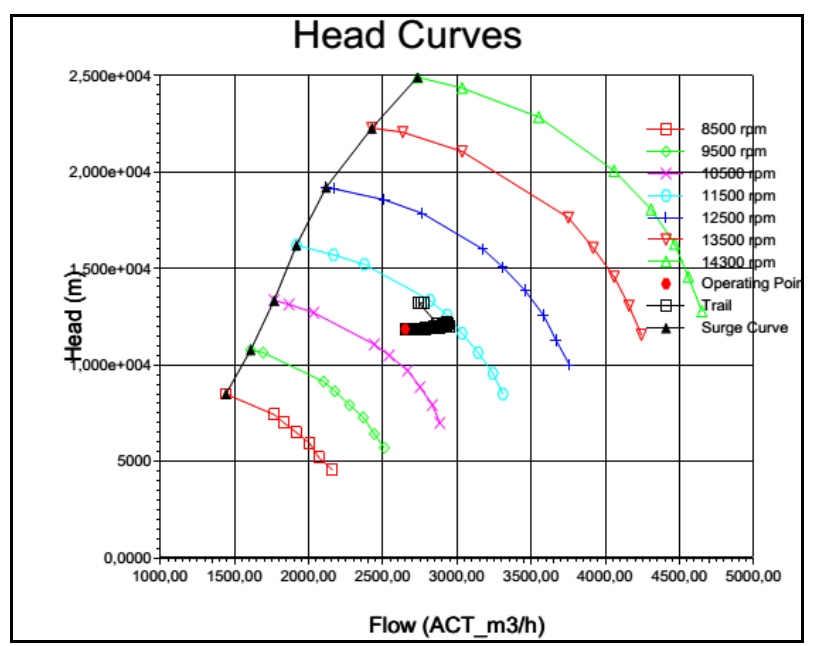

Fig. 7. Compressor Performance with a change in composition +2 $\mathrm{g} / \mathrm{mol}$

\section{Conclusion}

Simulation of gas compression systems in the dynamic state using a process simulator HYSYS has been successfully created and has stabilized. Models were made as detailed as possible in order to approach the actual condition of the plant. Some modifications were made such as the addition of control performance and load sharing. PID control parameters obtained by using Auto Tuning Variation method, almost the entire process variables are controlled by the PI controller except for temperature control using PID controllers. With scenarios such as a decrease in the input flow rate, low suction pressure, and changes in the 
composition will cause the compressor into the surge. In this Study, designed gas compression system has been able to prevent surge by regulating the ASC and ASV with the configuration offered on the simulation. Therefore the simulated disturbances are compensated by the system.

\section{Acknowledgment}

The authors would like to thank Mr. Dwi Yudha Prasetyatama and Pusat Studi Ilmu Teknik Universitas Gadjah Mada for providing data and consultations.

\section{References}

[1] BP3MD Sumatera Selatan, Mining and Energy 2014. Accessed on 13 April 2016. (in Bahasa Indonesia)

[2] Pertamina EP, Company Profile 2013. Accessed on 13 April 2016.

[3] Svrcek, W.Y. Mahoney, D.P. Young, R. Brent, A RealTime Approach to Process Control (John Wiley \& Sons, New Jersey, 2006)

[4] D. E. Seborg, T. F. Edgar, D.A. Mellichamp, Process Dynamics and Control (Wiley, New York, 1989)

[5] K.J. Astrom, T. Hagglund, Automatic tuning of PID [controllers (Instrument Society of America, New Concord, 1988).

[6] C.C. Hang, K.J. Astrom, Q.G. Wang, J. Process. Contr 12(1), 143-162 (2002)

[7] R. K. Herz, Closed-Loop Auto Relay Tuning - Auto Tune Variation, ATV. San Diego, University of California. 2012.

[8] C. Hansen. Dynamic Simulation of Compressor Control Systems. Esbjerg, 2008

[9] U.S. Paraguassu, Indian J. Sci. Technol 8 (2015).

[10] J. Liedman, R. Månsson, Dynamic simulation of a centrifugal compressor system, Gothenburg, 2013

[11] G.K. McMillan, Centrifugal and Axial Compressor Control (Instrument Society of America, New Concord, 1983)

[12] G. Towler, R. Sinnott, Chemical Engineering Design: Principles, Practice and Economics of Plant and Process Design Second Edition (Elsevier, Boston, 2013)

[13] R. Turton, R.C. Bailie, W.B. Whiting, J.A. Shaewitz, D. Bhattacharyya, Analysis, Synthesis, and Design of Chemical Processes Fourth Edition (Prentice-Hall, Upper Saddle River, 2012 